\title{
El Estado accionista: gobierno de las empresas públicas en Colombia y Francia**
}

\section{The State as shareholder: government of public companies in Colombia and France}

RESUMEN

El presente documento plantea un análisis comparativo de las medidas que vienen siendo adoptadas en Francia y en Colombia con el fin de racionalizar el gobierno de las empresas estatales. Pese a la política de privatizaciones que se ha implementado en los dos países desde mediados de los años ochenta, el rol del Estado como accionista de empresas públicas o de empresas de economía mixta tiene todavía un peso económico considerable. Se estudian las políticas sobre el Estado accionista, las instituciones que en ese marco se han adoptado y las influencias que han sido determinantes para su adopción. Se reflexiona sobre la forma en que las políticas adoptadas han pretendido superar la búsqueda de dos objetivos que, en principio, parecen antagónicos: de una parte, que el Estado se comporte como accionista privado que busca la rentabilidad de sus inversiones, y de la otra, que atienda el objetivo de la protección de interés general. Se concluye que la institución demanda un análisis reflexivo en el que se proteja, pero al mismo tiempo se limite, la racionalidad propia de los sistemas jurídico, económico y político.

PALABRAS CLAVE

Estado accionista, derecho económico, corporate governance, participaciones estatales, empresas públicas, juntas directivas.

Doctor en Derecho de la Universidad Paris-Dauphine, PSL Research University, magíster en Derecho de los Negocios y de la Economía de la Universidad Paris I Panthéon-Sorbonne. Asesor del Ministerio de Hacienda y Crédito Público y docente ocasional de Derecho Económico en la Universidad Nacional. Bogotá, Colombia. Contacto: jsanclementea@ gmail.com

Recibido el 18 de septiembre de 2017, aprobado el 4 de abril de 2018.

Para citar el artículo: SANCLEMENTE-ARCinIEGAS. J. El Estado accionista: gobierno de las empresas públicas en Colombia y Francia. En Revista Derecho del Estado, Universidad Externado de Colombia. N. ${ }^{\circ} 42$, enero-abril de 2019, pp. 249-278.

DOI: https://doi.org/10.18601/01229893.n42.09 
ABSTRACT

This document presents a comparative analysis of the measures that have been adopted in France and in Colombia in order to rationalize the government of State's enterprises. Despite the privatization policy that has been implemented in the two countries since the mid-1980s, the role of the State as shareholder of public companies or mixed economy companies still has a considerable economic weight. It analyzes the policies on the State shareholder, the institutions that have been adopted in that framework and the influences that have been decisive for its adoption. It reflects on the way in which the adopted policies have tried to surpass the search of two objectives that, in principle, seem antagonistic.

On the one hand, the State behaves as a private shareholder seeking the profitability of its investments, and on the other, the State as guarantor of the general interest. It is concluded that the institution demands a reflexive analysis in which the rationality of the legal, economic and political systems is protected, but at the same time limited.

\section{KEYWORDS}

State shareholder, Economic Law, Corporate Governance, State holdings, public enterprises, boards of directors.

\section{SUMARIO}

Introducción. 1. Transformaciones en el interior del sistema jurídico. 1.1. Hacia la adopción de un régimen de derecho privado. 1.2. Transformaciones de la estructura institucional: hacia la especialización administrativa. 1.3. Del Estado regulador al Estado accionista 2. El Estado accionista: repliegue de la influencia política sobre la economía. 2.1. Del gobierno político a la administración técnica de las empresas estatales. 2.2.Administración técnica e imparcialidad en el gobierno de las empresas públicas. 2.3. Exacerbación de los riegos propios de la corporate governace e independencia. 3. El énfasis en la racionalidad económica, hacia una mayor rentabilidad del capital. 3.1. El Estado accionista de empresas deficitarias. 3.2. La rentabilidad de las inversiones del Estado accionista. 3.3. Los límites a la racionalidad económica: el Estado no es un accionista como los otros. Conclusiones. Referencias.

\section{INTRODUCCIÓN}

El presente documento plantea un análisis comparativo de las medidas que vienen siendo adoptadas en Francia y en Colombia con el fin de racionalizar el gobierno de las empresas estatales. En él se analizan tanto los aspectos 
comunes como las principales diferencias. Como se verá, los dos Estados se han visto abocados a reconsiderar el asunto en razón de las inquietudes despertadas por la forma en que gestionan la participación pública en el capital de las empresas. Esas políticas han sido influenciadas por recomendaciones de instituciones internacionales como la ocDE ${ }^{1}$ y el Banco Mundial' quienes han subrayado la importancia de mejorar el gobierno corporativo de las compañías públicas con el fin de atender los conflictos de interés que se desprenden de las diversas funciones de las que es titular el Estado, así como los conflictos entre principal y agente que han sido identificados en las teorías del gobierno corporativo.

La importancia dada al asunto se justifica plenamente. Pese a la política de privatizaciones que se ha implementado desde mediados de los años ochenta, tanto en Francia como en Colombia, el rol del Estado como accionista de empresas públicas o de sociedades de economía mixta tiene todavía un peso económico considerable. En el análisis del año 2017, la "Cour des Comptes" francesa analiza la presencia del Estado francés en la economía a través de sus empresas, y afirma ${ }^{3}$ que ella se expresa en un número próximo a las 1.800 empresas, con un valor cercano a los cien mil millones de euros. Según dicho análisis, Francia es el país de la OCDE en el que el Estado emplea la mayor cantidad de personas, una cifra superior a las 780 mil. En Colombia, esa participación es menos importante en número de empresas y trabajadores, pero es aún más significativa en términos proporcionales. Según el Documento Conpes 3851 de 2015, el valor de los activos de las participaciones accionarias del Gobierno nacional corresponde a 240 billones, equivalente al 32\% del PIB del citado año. Esto, como resultado del desempeño de 111 empresas. A nivel internacional, el Banco Mundial ha señalado ${ }^{4}$ que las sociedades propiedad del Estado representan el 20\% de la inversión global, emplean el 5\% de la población total y en algunos países pueden representar hasta el $40 \%$ del PIB.

Pese a dicha importancia, la concepción del Estado accionista no es clara, se trata de una noción que plantea dificultades ya que no se adapta a enfoques formalistas. Es una institución que implica relaciones entre diferentes sistemas sociales y una simbiosis de categorías aquejadas por contradicciones en sus propiedades esenciales, convirtiéndola en un oxímoron. Para autores como David Azema, ella pretende un imposible jurídico ${ }^{5}$, por cuanto las finalidades, las reglas y la cultura del Estado son ontológicamente incompatibles con las de un accionista. Por ello, los términos Estado y accionista se opondrían

1 OCDE. Directrices sobre el gobierno corporativo de las empresas públicas. París: OCDE, 2011.

2 The World Bank. Corporate Governance of State-Owned Enterprises. Washington D.C., 2014.

3 Cour des Comptes. L'État actionnaire. Paris: La Documentation Française, 2017, 20.

4 The World BANK. Corporate Governance of State-Owned Enterprises, cit., XXI.

5 Azema, D. L'impossible État actionnaire? Paris: L'Institut Montaigne, 2017. 
hasta hacer imposible su coexistencia. Otros autores ${ }^{6}$ han observado que se trata de una institución que suscita perplejidad por el hecho de intentar conciliar nociones antagónicas. Por un lado, hace referencia al Estado como una persona jurídica de derecho público que persigue naturalmente objetivos de interés general. De otra parte, se refiere a la misma persona actuando a través de instituciones propias del derecho comercial, como el accionista y la sociedad anónima; mediante ellas debería perseguir la rentabilización de su inversión, actuando de la misma forma que cualquier inversionista privado.

Para desarrollar la reflexión propuesta se divide el artículo en tres partes. En la primera de ellas se analizan las transformaciones en el interior del sistema jurídico, observando la mutación que implica la noción de Estado accionista respecto de la naturaleza del régimen jurídico aplicable al asunto. En la segunda parte se estudian las trasformaciones que implica la institución en las relaciones entre el sistema jurídico y el sistema político. En la tercera parte se hace referencia a las relaciones entre el sistema jurídico y el sistema económico en torno a la noción del Estado accionista.

\section{TRANSFORMACIONES EN EL INTERIOR DEL SISTEMA JURÍDICO}

Las políticas adoptadas en Francia y en Colombia sobre el Estado accionista se inscriben dentro de una trasformación particular del sistema jurídico. Una mutación que se caracteriza por recurrir a instituciones de derecho privado para el ejercicio de actividades de la Administración Pública. Pese a ello, la función del Estado como propietario es confiada a nuevas entidades administrativas que deben especializarse en el desarrollo de los actos propios de un accionista. De manera que no se trata de una huida del derecho administrativo, sino de una nueva racionalidad en la actuación del Estado. La nueva institucionalidad es concebida como una instancia especial de la Administración, que desarrolla de manera autónoma esas tareas y que separa las funciones de accionista de otras competencias que desarrolla el Estado en la economía, en especial, de la actividad de regulación económica.

\subsection{Hacia la adopción de un régimen de derecho privado}

La adopción de políticas públicas dirigidas a racionalizar el rol del Estado, en tanto que accionista, puede ser interpretada como una nueva expresión particular de una mutación mayor de la estructura estática. Un cambio que da paso a lo que Chevallier ha denominado el Estado posmoderno ${ }^{7}$. En ese contexto, la distinción entre las categorías público/privado tiende a desvanecerse, los atributos simbólicos asociados a lo público -como el espacio de

6 CARTIER-BResson, A. L'État actionnaire. Paris: LGDJ, 2010.

7 Chevallier, J. L'État post-moderne, Paris, LGDJ, 2004. 
lo universal, del bien común o del interés general- son puestos en duda; para Sève, lo público habría perdido su aura positiva, habría caído de su trono ${ }^{8}$. En el régimen jurídico que regula el gobierno de las empresas estatales esa transformación se expresa por un cierto rechazo del derecho público ${ }^{9}$ y por la aceptación del derecho privado como nuevo marco legal de referencia.

El cambio apunta a garantizar la realización de nuevos valores que deben guiar la acción pública en el ámbito económico. La libertad económica, la rentabilidad de las inversiones, la eficacia, la eficiencia y la innovación son ahora los referentes orientadores de las políticas públicas en esa materia. Dichos factores se oponen a los defectos que se achacan a la intervención excesiva del Estado, que habría desembocado en la quiebra del modelo económico de la economía administrada ${ }^{10}$. Ese resultado se explicaría por los efectos adversos de la racionalidad burocrática sobre el sistema económico. La expresión jurídica de ese raciocinio se produce mediante una plétora de disposiciones de derecho público impuesta coercitivamente a los actores económicos. De allí que la pérdida de prestigio del Estado como operador económico se acompañe de la desconfianza hacia el instrumento a través del cual esa presencia toma forma: el derecho público y, en especial, el derecho administrativo.

La influencia que el Estado ejerce sobre sus empresas ha sido lograda tradicionalmente a través de la institución del control de tutela propio del derecho administrativo. Por el contrario, la nueva tendencia hace énfasis en instituciones propias del derecho privado, como la sociedad anónima y la calidad de accionista. A partir de ellas se otorga preponderancia a la racionalidad económica, en la búsqueda de la optimización financiera de las inversiones por medio de las buenas prácticas de gobierno corporativo que se orientan a la reorganización del proceso de toma de decisiones ${ }^{11}$. De manera paradójica, al privilegiar nociones de derecho privado se produce lo que Teubner ${ }^{12}$ designa como un rejuridificación de la institución. Así, la reflexión sobre el rol del Estado como accionista conduce a reforzar el condicionamiento jurídico del ejercicio de los poderes políticos y económicos que previamente eran ejercidos de manera discrecional.

8 SÈve, R. Presentation. En Le privé et le public, Archives de philosophie du droit. N. ${ }^{\circ}$ 41, 1997, 9-12.

9 DuRAn, P. Piloter l'action publique, avec ou sans le droit. En Revue Politiques et management public. Vol. 11, n. ${ }^{\circ}$ 4, 1993, 1-45

10 Aftalion, F. La faillite de l'économie administrée. Paris: PuF, 1990.

11 Von Tunzelmann, N. Historical Coevolution of Governance and Technology in the Industrial Revolutions. En Structural Change and Economic Dynamics. Vol. 14, n. ${ }^{\circ} 4,2003$, 365-384.

12 Teubner, G. Elementos materiales y reflexivos en el derecho moderno. En Bourdieu, P. y Teubner, G., La fuerza del derecho. Bogotá: Uniandes, Universidad Javeriana y Siglo del Hombre Editores, 2000, 81-152. 
De ese modo, el poder que el Estado ejerce sobre las empresas en cuyo capital participa tiende a alejarse del modelo de control que practica la Administración sobre sus entidades descentralizadas: el control de tutela. Esta institución, originaria del derecho administrativo francés, otorga al gobierno central un amplio conjunto de facultades mediante las cuales se asegura la subordinación de la Administración. La adopción de la tutela administrativa como el medio de gestión propio de las compañías públicas ha sido conside$\mathrm{rada}^{13}$ un producto de la inexperiencia del Estado en materia económica. En efecto, el Estado accionista es un corolario del Estado intervencionista, que, a su vez, es una mutación del Estado gendarme. Así, desde la perspectiva liberal clásica el Estado no actuaba como accionista de sociedades, y cuando a mediados del siglo xx el Estado francés desplegó una fuerte intervención en la economía acudió a las instituciones de derecho público, como, precisamente, el control de tutela, para asegurar el seguimiento de la actividad de sus empresas.

En las políticas del Estado accionista, la expresión de la lógica del derecho privado se dirige a abandonar el modelo según el cual las empresas en las que el Estado tiene participación deben gobernarse de acuerdo con las orientaciones de las autoridades políticas, como si fueran entes públicos. En su lugar, se propone que se gobiernen por las decisiones de las asambleas o juntas directivas, modo de gobierno que corresponde a su naturaleza jurídica como sociedades de derecho privado. Por ello, al tiempo que en Francia André Delion habla del paso del Estado tutor al Estado accionista ${ }^{14}$, en Colombia se cuestiona la pertinencia del marco jurídico que rige las empresas industriales y comerciales del Estado y las sociedades de economía mixta. Las críticas señalan que ese régimen legal se caracteriza por concebir a esas empresas como parte del estatuto básico de organización y funcionamiento de la Administración Pública, establecido en la Ley 489 de 1998. Se ha sostenido que se trata de un modelo complejo y disperso que no permite evaluar detalladamente la administración de las empresas y que conduce a un desempeño económico mediocre ${ }^{15}$.

Por consiguiente, la esencia de la política pública respecto del Estado accionista consiste en la adopción de medidas que se dirigen a garantizar que el poder que el Estado ejerce sobre las empresas se exprese a través de los instrumentos jurídicos con que cuentan los accionistas en la sociedad anónima; es decir, la integración de la junta directiva y la participación en la asamblea de accionistas. Con el fin de dotar al Estado de herramientas que le permitan llevar a cabo esa actividad de manera adecuada, se ha creado, tanto

13 Delion, A. De l'État tuteur à l'État actionnaire. En Revue française d'administration publique. N. ${ }^{\circ}$ 4, 2007, 537-572.

14 Ibíd.

15 Documento Conpes 3851 de 2015. 
en Francia como en Colombia, una nueva institucionalidad. Las nuevas entidades administrativas tienen el objetivo de realizar un seguimiento y control especializado del portafolio estatal. Además, la actividad de gobierno de las empresas tiende a delegarse en los órganos internos de las sociedades. Por esa razón, las nuevas instituciones se encargan de garantizar que el Estado elija bien sus representantes en las juntas directivas y en las asambleas de accionistas. De esa manera, ante la pérdida de prestigio del modelo de gestión pública, la racionalidad propia de los actores privados tiende a erigirse como el paradigma por seguir. El Estado es remplazado por el mercado, quien establece en últimas el modelo en temas de gobierno corporativo como en otros ámbitos sociales ${ }^{16}$. De allí que las políticas de gobierno de las empresas públicas traten de seguir las técnicas de administración de las empresas privadas. Esto por cuanto en dicho ámbito, desde hace tiempo, se ha desarrollado una profusa reflexión sobre la mejor forma de responder al desafío de asegurar una mayor eficacia, eficiencia y competitividad, al tiempo que se atienden los conflictos de interés entre los propietarios y los administradores.

\subsection{Transformaciones de la estructura institucional: hacia la especialización administrativa}

Tanto en Francia como en Colombia, las nuevas políticas públicas sobre el Estado accionista parten de una preocupación especial que plantea una toma de conciencia sobre la importancia de racionalizar ese rol del Estado. Dicha reflexión ha sido formalizada en documentos que proponen la implementación de políticas públicas específicas. En desarrollo de las recomendaciones formuladas, se han adoptado decretos que han creado nuevas instancias administrativas especializadas en el ejercicio del rol del Estado como accionista. Esas instancias han sido encargadas de ejercer el conjunto de funciones que se desprenden de la participación económica del Estado en las diferentes empresas.

En Francia, el 6 de noviembre de 2002, el ministro de Economía, Finanzas e Industria encargó a un grupo de trabajo, encabezado por René Barbier de La Serre, un estudio especial sobre las condiciones de ejercicio por el Estado de su actividad como accionista. Ese grupo de trabajo produjo un documento publicado el 23 de febrero de $2003^{[17]}$. En él se formulan recomendaciones tendientes a mejorar el ejercicio de los derechos y obligaciones del Estado

16 Frison-Roche, M-A. Le modèle du marché. En Archives de philosophie du droit. Vol. 40, 1995, 286-313.

17 BARBIER DE LA SERRE, R. Rapport "L'État actionnaire et le gouvernement des entreprises publiques". Disponible en: http://www.ladocumentationfrancaise.fr/rapports-publics/034000095/ index.shtml 
respecto a las empresas en las que actúa como administrador o accionista. La principal recomendación propuesta en dicho estudio se refiere a la creación de una entidad especializada, encargada de asumir las actividades propias del Estado accionista.

En Colombia, un análisis equivalente fue realizado en el Documento Conpes 3851 del 23 de noviembre de 2015. Entre sus primeras recomendaciones destaca la de crear, dentro de la estructura del Ministerio de Hacienda y Crédito Público, una nueva dirección general que ejerza las funciones del accionista en las empresas en cuyo capital la Nación tiene participación, siguiendo de esa manera el modelo francés.

Es de señalar, como una característica particular, que en los dos países la reflexión que condujo a la adopción de las políticas sobre el Estado accionista ha sido influenciada de manera determinante por la OCDE. Así, en el análisis realizado por Bruno Bézard y Éric Preiss ${ }^{18}$ se observa que la adopción de esas políticas en Francia atiende las directrices sobre el gobierno de las empresas púbicas formuladas por esa organización internacional en 2003. Y en Colombia, debido a las condiciones de admisión a la OCDE, esa influencia ha sido aún más significativa. De ese modo, las directrices emitidas en el año 2011 por esa entidad operaron también como marco de referencia. Se trata entonces de una clara muestra de que la desnacionalización de las políticas estatales, tal y como plantea Sassen ${ }^{19}$, es un fenómeno que afecta tanto a países periféricos como a países centrales.

La implementación de las políticas recomendadas se ha realizado mediante la expedición de normas que crean nuevas instancias administrativas. En Francia, esas políticas se han adoptado esencialmente por medio del Decreto 963 del 9 de septiembre de 2004 que creó la "Agence des participations de l'État" ${ }^{20}$. En Colombia, mediante el Decreto 2384 de 2015 se modificó la estructura del Ministerio de Hacienda y Crédito Público creando la Dirección General de Participaciones Estatales.

Ahora bien, cabe observar que la implementación de la política del Estado accionista ha sido mucho más robusta en Francia que en Colombia. En efecto, en el caso francés, el artículo primero del decreto citado crea una nueva entidad administrativa que ejerce en nombre del Estado las funciones propias de un accionista, y las actividades de la nueva entidad cobijan todas las empresas en las que el Estado tiene participación directa o indirecta, sea esta mayoritaria o minoritaria. En Colombia, por el contrario, no se trata de

18 BÉzArd, B. y Preiss, E. L'agence des participations de l'État. En Revue française d'administration publique. N. . 4, 2007, 601-613.

19 SASSEN, S. Desnacionalización de las políticas estatales y privatización de la producción de normas. En Teubner, G., Sassen, S. y Krasner, S., Estado, soberano y globalización. Bogotá: Siglo del Hombre Editores, 2010, 103-138.

20 Para un análisis detallado sobre la naturaleza de esa institución véase el ya citado texto de Bézard y Preiss. 
una nueva entidad administrativa, sino de una dirección general dentro de la estructura administrativa del Ministerio de Hacienda y Crédito Público.

En el caso colombiano, la política se encuentra aún en etapa de desarrollo. Por ello, de conformidad con lo previsto en el artículo 2. ${ }^{\circ}$ del Decreto 2384 de 2015, la Dirección General de Participaciones Estatales debe ejercer sus funciones "sin perjuicio del control administrativo que ejercen los Ministerios y Departamentos Administrativos sobre sus actividades adscritas o vinculadas". De manera que el tradicional control de tutela subsiste. Por el contrario, en Francia, la creación de la nueva entidad implica la transferencia de las funciones que el Estado ejercía antes por intermedio de los diferentes ministerios. El citado Decreto 963 de 2004 establece, sin embargo, que la Agencia de Participaciones del Estado deberá desarrollar su actividad en coordinación con los diferentes ministerios competentes, y para ello crea un comité de dirección del Estado accionista, integrado por los principales ministerios.

En cuanto a los otros aspectos, las funciones que se han asignado a las dos entidades son similares. Así, aparece como un rasgo común el desarrollo de una estrategia global con miras a optimizar las participaciones del Estado en las diferentes empresas. Sin embargo, tanto el legislador francés como el colombiano han trazado directamente los lineamientos principales de esa estrategia. A la nueva institucionalidad le corresponde solamente su desarro1lo. De entre los criterios comunes que han sido adoptados se destaca el de velar por el mejoramiento del gobierno corporativo de las empresas frente a las cuales deben desplegar sus funciones. Para ello, las entidades desarrollan actividades tendientes a integrar las juntas directivas con personal experto en las diferentes materias. Una vez designados los responsables del gobierno de las empresas, las entidades deben asegurar el seguimiento y la evaluación de la gestión de acuerdo con los objetivos que se han fijado previamente. Por último, aunque no aparece explícito en las normas de creación las nuevas instituciones, estas buscan evitar los conflictos que pueden desprenderse del ejercicio simultáneo de los diferentes roles que el Estado desempeña en la economía, especialmente del rol de regulador.

\subsection{Del Estado regulador al Estado accionista}

Las transformaciones del sistema jurídico que apuntan a la racionalización de la actividad del Estado como accionista son adoptadas al mismo tiempo que se ha aceptado la idea según la cual el Estado debería abandonar su participación directa en la actividad económica; sin embargo, la regulación económica se ha convertido en un escenario más adecuado para la acción estatal $^{21}$. De esa manera, los roles del Estado accionista y el Estado regulador

21 Para una introducción al derecho de la regulación económica ver FRISON-Roche, M-A. 
presentan una relación compleja pero complementaria. En Colombia se ha afirmado que "la regulación es la función estelar del Estado"22, cuya adopción también ha sido determinada por las influencias internacionales ${ }^{23}$, en especial la del derecho anglosajón ${ }^{24}$. En Francia, la importancia de la noción de regulación ha sido reconocida por numerosos autores. Así, Chevallier ${ }^{25}$ afirma que el concepto de regulación se ha convertido en un paradigma mayor de las ciencias sociales; Jeammaud ${ }^{26}$ señala que la noción se ha puesto tan de moda que es utilizada de manera equívoca e indiscriminada, y Autin ${ }^{27}$ observa que la fortuna del término "regulación" en el debate jurídico francés es simplemente asombrosa.

Dada la importancia que ha ganado y su carácter polisémico, el concepto de regulación ha sido utilizado para fundar a partir de él un nuevo tipo de Estado. Es así como Levi-Faur y Jordana ${ }^{28}$ hacen referencia a la regulación como la actividad emblemática del Estado, que anuncia un nuevo tipo de capitalismo. Y Majone observa que la relevancia que se otorga a la regulación permite identificar una transformación radical del Estado capitalista marcada por el abandono de un conjunto de actividades y por el advenimiento de la regulación como la principal de las funciones estatales $^{29}$. De allí que la noción de Estado regulador sea utilizada para describir esta trasformación de la forma estatal en diferentes latitudes. El hecho es que tanto la Unión Europea como comunidad de Estados ${ }^{30}$, como

Définition du droit de la régulation économique. En FRISON-Roche, M-A. (dir.), Les régulations économiques: légitimité et efficacité. Paris: Presses de Sciences Po y Dalloz, 2004, 7, y MArcou, G. La notion juridique de régulation. En Actualité Juridique Droit Administratif. 2006, 347-356.

22 LATORRE, I. La política de mejora regulatoria: oportunidades y desafíos para Colombia. En Revista de Derecho Público, Universidad de los Andes. N. ${ }^{\circ} 33,2014,2-35$.

23 Restrepo-Medina, M. Redefinición normativa de la regulación y el control de la actividad económica en el caso colombiano. En Universitas. Vol. 59, n. . 121, 2010, 263-304.

24 Sanclemente-Arciniegas, J. L'indépendance du régulateur en France et en Colombie. Tesis de doctorado en Derecho, Universidad Paris-Dauphine, PSL, 2016.

25 Chevallier, J. De quelques usages du concept de régulation. En Miaille, M. (ed.), La régulation entre droit et politique. Paris: L'Harmattan, 1995, 71-93.

26 Jeammaud, A. Introduction à la sémantique de la régulation juridique. En Clam, J. y Martin, G. (eds.), Les transformations de la régulation juridique. Paris: LGDJ, 1998, 47-72.

27 Autin, J. L. Réflexion sur l'usage de la régulation en droit public. En MaIlLE, M. (ed.), La régulation entre droit et politique. Paris: L'Harmattan, 1995, 43.

28 Levi-Faur, D. y Jordana, J. The Rise of Regulatory Capitalism: The Global Diffusion of a New Order. En The Annals of the American Academy of Political and Social Science. Vol. 598, n. $^{\circ} 1,200-217$.

29 Majone, G. From the Positive to the Regulatory State: Causes and Consequences of Chanmges in the Mode of Governance. En Journal of Public Policy. Vol. 17, n. ${ }^{\circ}$ 2, 1997, 139167.

30 Majone, G. La Communauté européenne, un État régulateur. Paris: Montchrestien, 1996. 
Francia $^{31}$ o Colombia ${ }^{32}$, han sido calificadas por los autores citados como Estados reguladores.

La relación entre las nociones de Estado accionista y Estado regulador es compleja, dado que esta última forma de Estado representaría la oposición al modelo intervencionista del que se deriva la participación del Estado en el capital de las empresas. El conflicto puede esquematizarse señalando que la participación púbica en la actividad económica es propia del modelo según el cual el Estado es el actor principal del juego económico. Por el contrario, la regulación implica que el Estado no participa en el juego, sino que es un tercero que actúa como un árbitro imparcial. De manera que los valores y herramientas jurídicos asociados a estas dos formas de presencia del Estado en la economía son disímiles. Hacer abstracción de ello conduce a permitir que quien debería actuar como árbitro se comporte como un actor más dentro del juego económico, beneficiando a las empresas en las que tiene participación.

Sin embargo, las políticas asociadas a esas dos formas de Estado son complementarias. Las dos iniciativas se proponen mejorar la presencia del Estado en la economía. En ese sentido, la eficacia y la imparcialidad aparecen como rasgos distintivos de las mediadas preconizadas. En cuanto a la eficacia, como se pudo apreciar en el numeral anterior, la sustitución del marco jurídico de derecho público por el del derecho privado se dirige a atender ese tipo de valores. En cuanto a la imparcialidad, para garantizar que el Estado no tome partido en el juego económico es imprescindible garantizar la independencia y la autonomía de las autoridades de regulación económica.

Además, las nociones de Estado regulador y Estado accionista son complementarias, en la medida en que plantean el repliegue de la dirección política sobre la actividad económica (ver $n .^{\circ} 2$ ). Ese repliegue toma la forma de una garantía especial de independencia y de autonomía de las autoridades de regulación y de la entidad que ejerce las funciones de accionista respecto de los responsables políticos del Estado. En materia de independencia de las autoridades de regulación, la situación de Francia y Colombia es divergente. En efecto, en Francia la independencia es garantizada sólidamente en el estatuto legal de esas autoridades. Por el contrario, en Colombia las autoridades regulación permanecen bajo el control de los responsables políticos ${ }^{33}$. En lo que se refiere a la autonomía de las entidades encargadas de ejercer la función de accionista en nombre del Estado, la situación es común en los dos países, puesto que se han adoptado instancias que se encuentran

31 Chevallier, J.L'État régulateur. En Revue française d'administration. N. ${ }^{\circ}$ 111, 2004/3, 481.

32 Alviar García, H. y Lamprea, E. (coords.). El Estado regulador en Colombia. Bogotá: Uniandes, 2015.

33 Para un análisis en profundidad al respecto, véase SAnClemente-Arciniegas. L'indépendance du régulateur en France et en Colombie, cit. 
sometidas a la dirección de autoridades políticas. En Francia, la ausencia de autonomía de la Agencia de Participaciones del Estado ha sido objeto de críticas. Así, el ya recordado estudio de la "Cour des comptes" sobre el Estado accionista recomienda ampliar la autonomía de la entidad frente al gobierno. En el mismo sentido, tanto la OCDE como el Banco Mundial, en los estudios precitados, se han pronunciado a favor de la autonomía del ente que ejerce la función de accionista.

\section{EL ESTADO ACCIONISTA: REPLIEGUE DE LA INFLUENCIA POLÍTICA SOBRE LA ECONOMÍA}

La adopción de políticas destinadas a racionalizar la actividad del Estado como accionista se inscribe dentro de una mutación general de la forma estatal. Un cambio caracterizado por la tendencia ${ }^{34}$ hacia el repliegue de la influencia de la política sobre la economía. En tal sentido, se ha hecho referencia a la desmitificación de la política ${ }^{35}$, ya que se duda de su condición de portadora de valores positivos asociados al interés general. Se plantea así una nueva relación entre el sistema político y el sistema económico, mediada por nuevas condiciones jurídicas para el ejercicio de la intervención política en la economía. Dicho repliegue se explica por factores como la corrupción, la ineficacia en la gestión política de las empresas, la toma de conciencia sobre la importancia de la experticia técnica en el gobierno corporativo, los conflictos de interés entre principal y agente, la ausencia de imparcialidad de los políticos y la importancia de sustraer la administración de las compañías de las coyunturas políticas de corto plazo. En Colombia, en desarrollo de esas iniciativas, desde el Documento Conpes 3851 de 2015 se adoptaron medidas tendientes a descontinuar la presencia directa de los ministros en las juntas directivas de las sociedades con participación estatal. Al mismo tiempo, la creación de la Dirección General de Participaciones Estatales en el Ministerio de Hacienda se orienta a garantizar que los integrantes de los órganos de dirección de las empresas estatales sean designados con fundamento en su experticia técnica.

En Francia, el repliegue de la influencia política en el derecho económico ha sido muy pronunciado ${ }^{36}$. A tal punto que Rosanvallon ${ }^{37}$ observa que, a partir de consideraciones técnicas que justifican la reducción de la influencia política sobre sobre la economía, se ha pasado a algo mucho más importante; una ilusión del capitalismo utópico que se funda sobre la idea de la abolición

34 Gargarella, R. Crisis de la representación política. México: Fontamara, 1997.

35 Chevallier, J. L'État post-moderne. Paris: LGDJ, 2004, 153.

36 De Smet, F-J. Déclin du politique et gouvernance publique. En Thirion, N., Crise et droit économique. Bruxelles: Larcier, 2014, 27-50.

37 Rosanvallon, P. Le capitalisme utopique, histoire de l'idée de marché. Paris: Seuil, 1999, VI. 
de la política como principal forma de organización social. La legitimidad de la transferencia del poder de los políticos a los expertos en materia de derecho económico ha sido objeto de duras críticas $^{38}$. Pese a ello, se han adoptado múltiples disposiciones legales que apartan a los políticos de diferentes ámbitos de la gestión económica ${ }^{39}$. De manera paradójica, las medidas tendientes a despolitizar la economía gozan de gran legitimidad debido a "la critique féroce dont les hommes politiques et la classe politique tout entière ferait l'objet" ${ }^{\prime \prime}$. En este sentido, el análisis de Rosanvallon ${ }^{41}$ ha explicado que, además de la legitimidad democrática, hay una legitimidad que se deriva de la imparcialidad y de la experticia. De allí que los responsables políticos, a pesar de estar investidos de la legitimidad derivada del sufragio, no serían considerados guardianes imparciales del interés general en diferentes áreas. Por tal razón, se justificaría confiar el gobierno de empresas públicas a expertos en la materia, ya que ellos son percibidos como actores más objetivos, más imparciales y, por lo tanto, más aptos para servir el bien común.

Es necesario tener en cuenta que lo que se censura es la influencia política guiada por intereses electorales de corto plazo. Sin embargo, las decisiones fundamentales que orientan la actividad de las empresas permanecen como un asunto de naturaleza intrínsecamente política, que debe ser resuelto por quienes se encuentran investidos de legitimidad democrática, principalmente a través de ley. Solo esas autoridades podrían decidir asuntos esenciales como la identidad pública de las empresas, o establecer que las mismas desarrollen actividades que se aparten abiertamente de la racionalidad económica ${ }^{42}$. Lo que expresan las políticas sobre el Estado accionista son objetivos de menor alcance, que se presentan en forma de nuevas restricciones jurídicas en nombre de imperativos técnicos y económicos ${ }^{43}$. Medidas que se dirigen a controlar tanto el ejercicio del poder político como la influencia ideológica sobre las empresas.

38 Deschamps, M. L'expert ou le peuple? Deux attitudes polaires face à la politique de concurrence. En RIDE. N. ${ }^{\circ} 1,2012,57-94$.

39 Esas políticas van desde la adopción de un banco central independiente para toda la zona euro hasta la creación de una nueva categoría de instituciones: las autoridades administrativas independientes, a las que se ha encargado la regulación económica, protegidas de la influencia política de corto plazo.

40 Rouban, L. Le pouvoir anonyme: les mutations de l'État à la française, Paris, Presses de la Fondation Nationale des Sciences Politiques, 1994.

41 Rosanvallon, P. La légitimité démocratique. Impartialité, réflexivité, proximité, Paris, Le Seuil, 2008, p 130.

42 Frison-Roche, M-A. Qu'est-ce que le service public? Point de vue juridique. En Revue de l'énergie. N. ${ }^{\circ} 486,1997,185$.

43 Louvaris, A. Lois techniciennes et droit à un procès équitable: le cas des lois de régulation économique. En Les Petites affiches. N. ${ }^{\circ} 134,60$. 


\subsection{Del gobierno político a la administración técnica de las empresas estatales}

Las iniciativas de racionalización de la actividad del Estado como accionista apuntan a mejorar el gobierno de las empresas a través de la reducción de la influencia política, en beneficio de una gestión determinada por criterios técnicos. Se produce de esa manera un cambio en los actores que ejercen influencias determinantes. Una mutación que da lugar a lo que García Pelayo ha denominado la remoción del político por el técnico ${ }^{44}$. Ello, por cuanto el pobre desempeño de la propiedad accionaria estatal estaría relacionado con la falta de experticia. El Estado no sabe ser propietario, afirma Azema ${ }^{45}$. En consecuencia, esas políticas plantean una sustitución tanto de las instancias de gobierno como de las personas llamadas a tomar las decisiones. En cuanto a las instancias, se genera un doble desplazamiento. De una parte, en el ámbito estatal, el centro de decisión tiende a concentrarse en la moderna entidad, especializada en el ejercicio de las competencias que se desprenden de la participación accionaria del Estado. De esa manera se agrupan en un solo centro de decisión las funciones que antes eran ejercidas en forma dispersa por diferentes entidades públicas. De otra parte, se produce un desplazamiento del centro de decisión empresarial, que antes estaba en una esfera administrativa interna al Estado. En su lugar, la nueva política plantea que el principal centro de decisión de las empresas sean sus órganos de dirección, de acuerdo con su naturaleza de sociedades comerciales.

En cuanto a las personas llamadas a tomar las decisiones, ese doble desplazamiento también opera. Así, dentro del Estado, los sujetos que antes tomaban las decisiones respecto de la orientación estratégica de las empresas eran los responsables políticos. Ellos fungían como la autoridad jerárquica en las autoridades administrativas que ejercía el control de tutela. Bajo la nueva política, ese poder tiende a ser ejercido por los integrantes de la entidad estatal especializada que ha sido creada para ejercer las labores del Estado accionista. Ese desplazamiento se ha configurado incluso en Colombia, donde, como ya se ha señalado, la Dirección General de Participaciones Estatales del Ministerio de Hacienda no ha remplazado a los ministerios que ejercen la tutela sobre las empresas. Pese a esto, esa dependencia cuenta con facultades para proponer una orientación estratégica de todas las empresas que tienen capital estatal. De manera que, si bien la facultad de orientación subsiste en los ministerios que actúan como cabeza del sector administrativo respectivo, ella debe ser ejercida atendiendo los criterios que se definan en la nueva instancia. De otra parte, se produce un desplazamiento del centro de decisión empresarial, hacia los órganos directivos de las sociedades, lo

44 García-Pelayo, M. Burocracia y tecnocracia. Madrid: Alianza, 1987, 33.

45 Azema. L'impossible État actionnaire?, cit. 
que implica naturalmente un cambio del titular del poder de decisión. Esa competencia pasa a radicarse en cabeza de quienes son nombrados para integrar las juntas o asistir a las asambleas. En todo caso, la fuente de la que se deriva la influencia se ha desplazado, ya no basta con la legitimidad que tienen las autoridades políticas para designar a individuos de su confianza, el conocimiento sobres los asuntos por tratar se ha tornado fundamental.

Esto corresponde a un enfoque en el que el conocimiento se convierte en el fundamento de la justificación de las decisiones. Así, la experticia técnica se utiliza como argumento de autoridad en el debate político. A partir del dominio técnico de los asuntos por tratar se estructura una de las condiciones esenciales con que debe contar un buen administrador: la independencia de criterio. Esas tendencias gozan de legitimidad ante las reiteradas crisis económicas y los escándalos de corrupción que han afectado a las empresas púbicas. De manera que las políticas del Estado empresario se revelan como una solución superior al modelo de administración tradicional dirigido por los responsables políticos. Las políticas sobre el Estado accionista recogen ese tipo de inquietudes al tratar de dotar al Estado de las herramientas conceptuales que le permitan desarrollar con eficacia su participación en el capital de las empresas. La iniciativa parte de constatar la inadecuación de las instancias administrativas tradicionales, en lo que se refiere a los conocimientos técnicos. De manera que la toma de conciencia sobre la complejidad técnica ${ }^{46}$ que involucra el gobierno de las empresas públicas es un factor clave en la creación de nuevas instancias. De allí se deriva la pertinencia de convocar a nuevos actores, que dominan los conocimientos considerados necesarios para enfrentar esos desafíos.

El cambio que representan instituciones como la del Estado accionista puede explicarse por el lugar que hoy en día ocupan el conocimiento y sus detentores en la escala de valores sociales. En efecto, en la sociedad del conocimiento, la experticia se convierte en un elemento clave en la distribución del poder. Por ello, sus titulares acumulan cada vez más prerrogativas. Así, desde 1979, Jean-François Lyotard ${ }^{47}$ se ha referido al conocimiento como un factor indispensable del funcionamiento de la sociedad posmoderna, cuya preponderancia habría llevado a una transformación de la clase dominante, que ya no estaría constituida por los políticos tradicionales sino por los depositarios del saber. Por lo tanto, los técnicos, que tradicionalmente estaban en la sombra de los políticos, abandonan su lugar de reserva, dejan de asesorar, para encargarse de implementar directamente las políticas públicas que anteriormente se limitaban a recomendar. Sin embargo, como ya se ha dicho, la noción del Estado accionista no prescinde de la influencia política. 
Autores como Ramos Jiménez ${ }^{48}$ y De Lucas y Murillo de la Cueva ${ }^{49}$ afirman que el fenómeno corresponde a lo que Maurice Duverger denominara la tecno-democracia. Esto es, un modelo concebido para atender la complejidad técnica de las decisiones, en donde los expertos son llamados a jugar roles protagónicos sin desconocer la importancia de la política.

\subsection{Administración técnica e imparcialidad en el gobierno de las empresas públicas}

Mientras que en Francia la adopción de políticas tendientes a racionalizar el Estado accionista atiende exigencias de una nueva fuente de legitimidad basada en el conocimiento, en Colombia esas iniciativas pueden ser identificadas como una revalidación de lo que López Medina ha denominado nuestro sueño weberiano ${ }^{50}$, que permanece esquivo. De esa manera se refiere a la continua búsqueda del ideal de una burocracia técnica y eficiente, aislada de las influencias políticas de corto plazo. El remozamiento de esas ideas se presenta dentro de un contexto en el que los técnicos gozarían de un prestigio especial para realizar la tarea de dirección de las instituciones encargadas de la intervención del Estado en la economía. Esa confianza es correlativa con la pérdida de la credibilidad de los políticos, quienes debido a la parcialidad partidista y a las inclinaciones ideológicas son considerados como inaptos para llevar a cabo la actividad de administrar las empresas públicas.

En efecto, la separación de la influencia política del gobierno de las empresas públicas se inscribe en una corriente más amplia, presidida por un razonamiento que tiende a sospechar de la imparcialidad de las decisiones de los responsables políticos. Las teorías que sospechan de los titulares de autoridad, en la conducción imparcial de los asuntos públicos, son antiguas y provienen de diferentes vertientes ideológicas. Desde su origen, el Estado liberal se funda en la idea de limitar el poder, dividiéndolo y sometiendo a quienes lo detentan al cumplimiento del principio de legalidad. Las críticas marxistas se basan precisamente en el reproche de la parcialidad del Estado, que sería solo la expresión de los intereses de la clase capitalista. Más recientemente, economistas liberales han formulado objeciones sobre la imparcialidad de las decisiones de las autoridades políticas. Así, Buchanan

48 Ramos Jiménez, A. Las formas modernas de la política. Estudio sobre la democratización de América Latina. Mérida: Centro de Investigaciones de Política Comparada, 2016, 105.

49 Murillo de La Cueva, F. Ideología, tecnocracia y liberalismo. En Revista Barataria Castellano-Manchega de Ciencias Sociales. $\mathrm{N}^{\circ}$ 6, 2003-2004, 47-72.

50 LÓPEZ MEDINA, D. El sueño weberiano. Claves para una comprensión constitucional de la estructura administrativa del Estado colombiano. En Revista de Derecho Público, Universidad de los Andes. Vol. 19, 2006, 11. 
y Tollison ${ }^{51}$ formularon la teoría de la elección pública, sosteniendo que, al contrario de lo que los políticos proclaman, las decisiones que estos toman no buscan proteger el interés general, sino que tienden a favorecer su interés particular. En sentido similar, Stigler ha planteado la idea según la cual la intrusión que el Estado realiza en la economía mediante la regulación no consulta el interés general, encontrándose más bien capturada por los intereses de los actores que operan en los sectores objeto de intervención ${ }^{52}$.

Debido a esas sospechas se ha generado lo que Rosanvallon ha identificado como el advenimiento de una nueva época: la edad de la desconfianza. Dentro de ella predomina la exigencia de una imparcialidad radical ${ }^{53}$, que ha dado origen a un amplio número de instituciones puestas por fuera de la dirección de los responsables políticos. Esas entidades actúan en diversos ámbitos de la actividad social, pero son especialmente visibles en materia de intervención del Estado en la economía. Los bancos centrales y las autoridades de regulación independientes, que operan en diferentes sectores económicos, son una expresión de esas exigencias. La creación de una nueva institucionalidad para atender los desafíos que plantea la participación del Estado en el capital de las empresas participaría de esa misma tendencia. Ello por cuanto la racionalidad partidista, propia de los actores políticos, se adapta mal a los imperativos de imparcialidad de la época naciente y a los retos que debe afrontar el buen manejo de empresas.

De otra parte, el marco temporal propio de la racionalidad política puede constituir un riesgo que influencia de manera negativa el desarrollo estable y a largo plazo de las empresas en las que el Estado tiene participación. En efecto, la celebración periódica de elecciones inclina a los responsables políticos a instrumentalizar las empresas con el fin de aumentar o salvaguardar su poder. Del mismo modo, las incertidumbres inherentes al proceso político representan riesgos para el desarrollo estable de los proyectos empresariales. La política se caracteriza por la posible alternancia de partidos en el poder, que pueden cambiar en períodos más cortos que los tiempos necesarios para que se produzca el retorno de grandes inversiones.

\subsection{Exacerbación de los riegos propios de la corporate governance e independencia}

Por las razones ya señaladas en los numerales 2.1 y 2.2 , en el caso del gobierno de las empresas públicas los riesgos que han sido identificados tradicional-

51 Buchanan, J. y Tollison, R. The Theory of Public Choice. Ann Arbor: University of Michigan Press, 1984.

52 Stigler, G. The Theory of Economic Regulation. En The Bell Journal of Economics and Management Science. 2, 1971, 3-21.

53 Rosanvallon, P. La contre-démocratie. La politique à l'âge de la défiance. Paris: Seuil, 2006, 16. 
mente en la teoría de la corporate governance ${ }^{54}$ se intensifican de manera considerable. Por consiguiente, resulta aún más pertinente la aplicación de las soluciones que esa teoría preconiza a nivel internacional: la independencia de las juntas directivas ${ }^{55} \mathrm{y}$ de los órganos de control. En efecto, la corporate governance se funda en el reconocimiento de los conflictos de interés entre los dueños del capital (principal) y los administradores de las empresas (agente). Dado que los primeros delegan en los segundos la administración de la empresa, el principal desconoce con exactitud el estado de los negocios administrados, hecho que es bien conocido por los administradores. De allí se derivan dos riesgos que la doctrina ha identificado ${ }^{56}$ como esenciales: de un parte, un riesgo moral, esto es, que el agente no actúe de acuerdo con los intereses del principal, sino que oriente su actuación en su propio provecho; de la otra, que el agente sea incompetente para desempeñar la responsabilidad encomendada, pero que el principal no lo sepa, debido a las asimetrías de información.

En el caso de las sociedades en las que el Estado tiene participación, los riesgos anotados se incrementan debido a que el nivel de delegación se profundiza. En efecto, el principal es la nación colombiana, que es en últimas el propietario. Ella delega en sus responsables políticos (Presidente de la República) la dirección de las empresas públicas. Esta función del Jefe del Ejecutivo es a su vez delegada en los ministros por la Ley 489 de 1998 , en virtud de la cual estos actúan como cabezas del sector y designan los miembros de las juntas directivas. De manera que la distancia entre el principal y su representante en la junta se amplía. Esto intensifica los riesgos de conflictos de interés, en la medida en que cada una de las instancias de decisión mencionadas puede verse tentada a anteponer su propio provecho a los intereses del principal. Por ello, para el caso de las empresas públicas resulta aún más relevante que en las empresas privadas adoptar medidas para garantizar el control efectivo de la gestión. En este sentido debe darse prioridad a la actividad propia de la corporate governance consistente en "confeccionar normas e incentivos, contratos tácitos o explícitos, que alineen efectivamente el comportamiento de los agentes con las pretensiones del principal, por medio de un reparto óptimo de los riesgos, bajo condiciones de incertidumbre" 57 .

54 Para una aproximación inicial a esa teoría véase Jensen, M. y MeckLING, W. Theory of the Firm: Managerial Behavior, Agency Costs and Ownership Structure. En Journal of Financial Economics. Vol. 3, n. ${ }^{\circ}$ 4, 1976, 305-360.

55 ReCODER DE CASSo, J. C. El papel de los independientes en los consejos. Una prioridad mundial. En Boletín Económico del ICE. 2006, 15-30.

56 Ganga Contreras, F. A. y Vera Garnica, J. R. El gobierno corporativo: consideraciones y cimientos teóricos. En Cuadernos de Administración. Vol. 21, n. ${ }^{\circ}$ 35, 2008, 93-126.

57 Ibíd. 
La principal solución que preconiza la teoría de la corporate governance hace énfasis en garantizar que la gestión de los administradores sea controlada por miembros de la junta directiva independientes de la administración ${ }^{58}$. En ese aspecto, el dispositivo legal francés resulta mucho más idóneo que el colombiano. Colombia ha reproducido tradicionalmente diseños institucionales excluyentes en los que el Presidente de la República acumula en exceso poderes que son ejercidos discrecionalmente. Esto facilita la captura de rentas por las personas que tienen acceso a su círculo de influencias, generando en últimas pobreza, desigualdad y exclusión ${ }^{59}$. En el caso de las políticas sobre el Estado accionista se repite ese patrón. En efecto, el ordenamiento legal de Colombia permite que, en realidad, la nominación de todos los miembros de las juntas directivas o asambleas dependa de la voluntad discrecional del Presidente o de funcionarios que son de su libre nombramiento y remoción. Por el contrario, en Francia, ese poder no está concentrado ya que, de una parte, a la cabeza del Estado y del Gobierno se encuentran dos personas diferentes, el Presidente y el Primer Ministro De otro lado, existe desde hace tiempo una ley de democratización del servicio público ${ }^{60}$ que establece directamente la integración de las juntas directivas de las empresas del Estado. Esa norma consagra la participación de un conjunto variado de sectores de la sociedad en las juntas directivas, destacándose la presencia de trabajadores, en algunos eventos de los usuarios, y en todos los casos de expertos nombrados en consideración de sus competencias técnicas.

Una configuración legal que asegure la composición heterogénea de las juntas y garantice la experticia técnica y el origen diverso de sus miembros posibilita que esas instancias actúen como espacios de reflexión y de intercambio de ideas, en los que se controla objetivamente el desempeño de las empresas. De esa manera se asegura una mejor protección del interés general. En ese sentido, los análisis que se han hecho sobre la situación en países de América Latina recomiendan superar "la deficiencia en los procesos de postulación y selección de miembros de la Junta Directiva, que permitan empoderar completamente a este órgano e incrementar su nivel de profesionalismo e independencia" ${ }^{61}$. Esto se explica por cuanto, si los integrantes de las juntas expresan solamente el punto de vista del gobierno, no cuentan con la libertad ni la autonomía de criterio, ya que acumulan indebidamente la expresión de los intereses del agente y del principal. Por ello, se preconiza

58 Rosenstein, S. y JefFrey, W. Outside Directors, Board Independence, and Shareholder Wealth. En Journal of Financial Economics. Vol 26, n. ${ }^{\circ} 2$, 1990, 175-191.

59 Acemoglu, D. y Robinson, J. Por qué fracasan los países. Bogotá: Planeta, 2012.

60 РRÉтот, X. L'administration des entreprises publiques: A propos de la loi $n^{o}$ 83-675 du 26 juillet 1983 rélative a la démocratisation du secteur public. En La Revue Administrative. Vol. 37, n. ${ }^{\text {o } 217, ~ 1984, ~ 29-38 . ~}$

61 Bernal, A. et al. Gobierno corporativo en América Latina. Importancia para las empresas de propiedad estatal. Caracas: CAF, 2012. 
la necesidad de sustraer la provisión de esos cargos de influencias políticas, y de permitir el florecimiento de un mercado del talento para los administradores independientes ${ }^{62}$.

El tema del monitoreo y control del desempeño de los administradores es la otra solución que preconiza la corporate governance. En ese sentido, al adoptar la Dirección General de Participaciones Estatales, la política colombiana sobre el Estado accionista se inscribe dentro de las tendencias modernas que ha seguido Francia. En efecto, la creación de esa dependencia dota al Estado colombiano de recursos humanos altamente calificados que cuentan con competencias adecuadas para realizar un seguimiento más cercano del desempeño de las empresas. Sin embargo, hasta el momento las medidas previstas se encuentran inconclusas, haciéndose necesario concluir la implementación de esa política con la adopción de una única entidad en la que se centralicen todas las participaciones del Estado. Ese paso se encuentra previsto en el Documento Conpes 3851 de 2015. La nueva institución reforzará la autonomía y la independencia en el ejercicio de la propiedad accionaria pública. Además, su puesta en funcionamiento implicará reducir la influencia que tienen los diferentes ministerios en las empresas que actúan en los sectores de su competencia.

\section{EL ÉNFASIS EN LA RACIONALIDAD ECONÓMICA, HACIA UNA MAYOR RENTABILIDAD DEL CAPITAL}

La racionalidad que orienta las políticas sobre el Estado accionista se dirige esencialmente a mejorar el desempeño económico de las empresas, esto con el fin de lograr retornos más altos para las inversiones públicas. Así, tanto las trasformaciones del sistema jurídico en busca de mayor eficiencia como las normas adoptadas para sustraer la gestión de las empresas de los intereses políticos de corto plazo responden a la lógica propia del sistema económico que tiende a maximizar las ganancias. Sin embargo, llevada a su extremo, esa concepción desconocería la esencia misma del Estado, que al tenor de la jurisprudencia de la Corte Constitucional es un ente ontológicamente cualificado ${ }^{63}$. Por ello, el sistema jurídico condiciona la racionalidad económica, de manera que toda participación del Estado se encuentra impregnada de los valores y principios establecidos en la Constitución.

62 The World Bank. China's Management of Enterprise Assets: The State as Shareholder. Washington D.C., 1997.

63 Corte Constitucional. Sentencia C-074 de 1993. 


\subsection{El Estado accionista de empresas deficitarias}

La situación de las empresas estatales deficitarias, en Francia como en Colombia, representa un desafío especial para las estrategias que tienden a racionalizar la participación del Estado en su capital. En efecto, esas políticas se oponen nítidamente a las lógicas que subyacen tanto a la retórica neoliberal como a los enfoques estatistas, que usualmente confluyen en torno al tema. De una parte, en el caso de las ideas neoliberales, la concepción que ha planteado desde fin de los años ochenta el banco Mundial en sus análisis sobre el gobierno de las compañías públicas señala ${ }^{64}$ que hay un consenso acerca de que el sector público es menos eficaz que el privado. Por ello, las empresas estatales serían ineficientes y deficitarias, hecho que las convierte en una carga para los presupuestos nacionales, frenando de esa manera el crecimiento y el desarrollo. Sin embargo, por diferentes razones, el fenómeno del Estado accionista persiste, la importancia económica de la presencia pública en el capital de las empresas de los países sigue siendo fundamental y parecería inevitable. Por ejemplo, en Francia, el Consejo Constitucional ${ }^{65}$ ha limitado drásticamente la posibilidad de privatizar compañías, por considerar contraria a la Constitución la transferencia de la propiedad de empresas de servicios públicos que actúan en condición de monopolio.

Ante la inevitable existencia del Estado accionista es necesario adoptar normas que tiendan a disociar su participación económica en las empresas del estigma de ineficiencia con el que se le asocia en la retórica neoliberal. A esos efectos es pertinente determinar si las sociedades son deficitarias por factores asociados a una mala gestión o si los resultados económicos negativos son motivados por una política estatal expresa. En el primer caso, una aplicación eficaz de las políticas del Estado accionista debería transformar la empresa logrando un desempeño que no afecte de manera negativa el presupuesto del Estado. En la segunda eventualidad resulta necesario que la Administración haga explícitos y financie debidamente los objetivos no económicos que asigna a sus empresas.

De otra parte, el análisis comparativo del Estado accionista en Francia y en Colombia muestra características que cuestionan también la lógica de quienes defienden el intervencionismo estatal en la economía. En efecto, el sistema jurídico francés, influenciado de manera determinante por las normas de la Unión Europea ${ }^{66}$, condiciona jurídicamente la aspiración de las sociedades deficitarias que pretenden ser financiadas por el Estado. Allí se encuentra

64 THe World BAnK. Bureaucrats in Business. The Economics and Politics of Government Ownership. Washington D.C., 1995.

65 Conseil Constitutionnel. Sentencia 86-207 de 26 de junio de 1986. Ver el comentario de Amadei, J-P. Vers la constitutionnalisation du domaine public. En Les Petites Affiches. 1995, 19.

66 Artículo 87.1 del Tratado de Roma, hoy artículo 103 del TFUE. 
un referente oportuno, dado que el derecho de la Unión apunta a la creación de un mercado único, y por consiguiente impide las ayudas económicas del Estado a las empresas que compiten en el espacio económico común. De esa manera se imposibilita que cada Estado miembro apoye financieramente a sus compañías nacionales en la disputa económica, pues ello falsearía las reglas de la libre competencia en toda la Unión. En el mismo sentido, Lombard ${ }^{67}$ observa que las disposiciones europeas que prohíben las ayudas estatales chocan de frente con la tradición francesa. En ella, el Estado tiende a asignar a sus empresas diferentes roles de tipo social, como la lucha contra crisis económicas o la preservación del pleno empleo.

Así las cosas, en Francia, el ejercicio de los poderes propios del Estado accionista se realiza respetando la Directiva de la Comisión del 25 de junio de 1980 que impone la transparencia en las relaciones financieras de los Estados y las empresas públicas. Como lo señala Delion ${ }^{68}$, la transparencia no impide que el Estado concurra al financiamiento de empresas deficitarias, sin embargo, impone un análisis detallado de los diferentes tipos de ayuda que una sociedad puede recibir del Estado. De esa forma se garantiza que los recursos públicos se dirijan prioritariamente a financiar las misiones de interés general asignadas a las empresas. Por consiguiente, no son financiables con recursos públicos los déficits de las empresas que se deriven de una gestión económica mediocre o que son consecuencia de un personal directivo incompetente que no es monitoreado eficazmente. Como tampoco pueden ser asumidas por el erario las pérdidas que sean la consecuencia de la captura política de las compañías por los intereses políticos de corto plazo.

Países que desean mantener una fuerte presencia de las empresas estatales en la economía han reconocido la pertinencia de realizar esfuerzos con miras a mejorar el gobierno de las sociedades ${ }^{69}$. Conviene resaltar que empresas públicas que generen déficits son plenamente viables dentro de una concepción democrática. Sin embargo, el carácter ineficiente y deficitario de las empresas públicas no constituye una fatalidad inevitable. En Francia, el país de la OCDE con más alta existencia de empresas estatales, la naturaleza pública de algunas de sus empresas no puede ser modificada debido a restricciones constitucionales, razón por la cual se ha visto en la necesidad de adoptar normas que mejoren el desempeño de sus compañías, conservando su identidad pública pero reduciendo los riesgos que se derivan de una gestión mediocre o contraria al interés general.

67 LOMBARD, M. Les conséquences juridiques du passage de l'État propriétaire à l'État actionnaire: les contraintes du droit de la concurrence. En Revue française d'administration publique. N. ${ }^{\circ} 4,2007,573-584$.

68 Delion. De l'État tuteur à l'État actionnaire, cit.

69 Barrera Rodríguez y López Domínguez. L'entreprise d'État à Cuba: tensions et changement, cit. THE WORLD BANK. China's Management of Enterprise Assets: The State as Shareholder, cit. 


\subsection{La rentabilidad de las inversiones del Estado accionista}

Las medidas que han venido siendo adoptadas, en Francia y en Colombia, con el fin de racionalizar la actividad del Estado accionista otorgan una importancia especial al objetivo de asegurar un retorno adecuado para las inversiones públicas. En tal sentido, en el Documento Conpes 3851 de 2015 se hace referencia a las deficiencias en el manejo del portafolio. Esa es una de las justificaciones para la adopción de la nueva política pública sobre las participaciones que el Estado colombiano tiene en las empresas. Según ese documento, se trata de mantener propiedades accionarias de alta rentabilidad como fuente de ingresos fiscales. Por eso, el Decreto 2384 de 2015 dispone que uno de los objetivos de la Dirección General de Participaciones Estatales es la generación de valor del patrimonio estatal. De otra parte, también en Francia, obtener una mejor rentabilidad del capital que el Estado posee en las empresas es uno de los fines identificados en el estudio ${ }^{70}$ que dio origen a esa política pública. En el citado documento se afirma que, para una compañía, la obligación de generar rentabilidad no es un asunto de ideología sino la garantía de su perennidad.

Sin embargo, el afán de obtener rendimientos adecuados de las inversiones púbicas en las empresas implica riesgos. Por un lado, está el riesgo regulatorio, pues en este caso resulta aún más pertinente la separación de la misión de explotación económica respecto de las funciones de regulación que adelanta el Estado. La idea es evitar que, en busca de apropiar recursos para financiar el presupuesto, la Administración autorice que las empresas desarrollen estrategias económicas en perjuicio de los consumidores o de la sociedad en general. Frente a ese tipo de conflictos, en Francia se ha hecho eco de la concepción alemana ${ }^{71}$ según la cual se encuentra prohibido que el Estado desarrolle iniciativas empresariales con el único objetivo de recaudar dinero para el físco. Así, toda presencia estatal en empresas debería responder a la realización de actividades de interés general. De otra parte, la búsqueda de rentabilidades más altas supone también asumir mayores riesgos. Por lo tanto, es necesario permitir que las empresas constituyan reservas suficientes, a fin de contar con un margen de maniobra financiero que les permita desarrollar de manera adecuada sus proyectos de desarrollo.

De manera que las estrategias del Estado accionista para obtener una rentabilidad adecuada de sus inversiones deben considerar diversos intereses en juego, tratando de armonizarlos. En primer lugar, proteger el patrimonio público; la Nación es el principal, es decir, quien recibirá la rentabilidad

70 BarbiER de LA SERRE. Rapport "L'État actionnaire et le gouvernement des entreprises publiques", cit.

71 WÜRTENBERGER, T. y NEIDHARDT, S. L'État actionnaire en Allemagne. En Revue française d'administration publique. N. . 4, 2007, 585-599. 
generada. Pero también el interés privado, dado que, en algunos casos, junto al Estado existen accionistas minoritarios, quienes en desarrollo de las políticas de gobierno corporativo son objeto de una protección especial, a fin de darles un tratamiento equitativo, similar al del accionista mayoritario, proporcionándoles información completa y asegurando su participación en los dividendos de la empresa. Además, deberá tenerse en cuenta el interés propio de la empresa, que en ocasiones puede ser contrario a la legítima aspiración de los accionistas de obtener elevados dividendos en todos los ejercicios. En fin, la implementación de las políticas deberá tener en cuenta que el Estado no es un accionista como los otros.

\subsection{Los límites a la racionalidad económica: el Estado no es un accionista como los otros}

Las políticas sobre el Estado accionista en Francia y en Colombia tienden a implementar normas de derecho comercial. Se sigue así el modelo de administración de las empresas privadas y se concibe al Estado desde la racionalidad propia de un accionista ordinario. Sin embargo, desconocer la naturaleza intrínseca del Estado puede conducir a errores, cuyos efectos serán una implementación fallida de la política mencionada. Por ello, resulta necesario reconocer plenamente la complejidad de la situación y diversidad de las situaciones. De un lado, la participación estatal en todas las empresas no tiene la misma importancia, hay empresas con mayoría estatal, unas de economía mixta y otras en las que la propiedad pública es marginal. Del otro lado, las nuevas medidas no suprimen el régimen de derecho público que ha gobernado tradicionalmente la institución, lo que se presenta es un escenario propio del derecho económico, en el que se da una interpenetración de técnicas e instituciones propias del derecho público y del derecho privado. Como afirma Duran ${ }^{72}$, en la gestión de las empresas pública debe tenerse en cuenta que no es posible recurrir a un enfoque simplista respecto de un universo complejo. Es necesario adoptar una perspectiva que integre el rigor en el seguimiento y control de los administradores, con garantías que permitan la flexibilidad necesaria para que la dirección pueda actuar ágilmente.

La principal dificultad viene de la pretensión de concebir las participaciones del Estado en las empresas desde la pura racionalidad económica. Esa concepción choca con la naturaleza estatal intrínseca, en tanto que ente instituido constitucionalmente, con unos fines específicos. Dentro de los cuales no se encuentra previsto el de generar utilidades. Tal y como lo ha señalado la jurisprudencia de la Corte Constitucional, también en el ámbito económico, el Estado debe "operar conforme a los valores y principios rectores que la Carta consagra, así como procurar la plena realización de los

Duran. Piloter l'action publique, avec ou sans le droit, cit. 
derechos fundamentales" 73 , ya que se encuentra sometido a un marco económico ontológicamente cualificado. El Estado no es entonces un accionista ordinario. Al contrario del accionista previsto en el código de comercio, de la Administración no se presume el ánimo de lucro. Sin embargo, como lo señala Lombard $^{74}$, una vez que ha optado por ser propietario, el Estado no puede ignorar las consecuencias jurídicas de esa elección. El Estado es entonces un accionista, pero un accionista atípico ${ }^{75}$. Es necesario que combine en su actividad las restricciones que se derivan de su naturaleza impregnada de valores superiores con la dirección y monitoreo eficaz de sus participaciones en el capital de las empresas.

La pertinencia de establecer límites a la racionalidad económica, que presiona hacia la obtención de mayores rentabilidades, se justifica ante la importancia que ha tomado en los últimos años el enfoque puramente mercantilista del Estado. Supiot ${ }^{76}$ designa esos riesgos como los del mercado total, por cuanto se pretende desconocer la naturaleza especial de los asuntos públicos y someter a la lógica mercantil absolutamente todos los aspectos

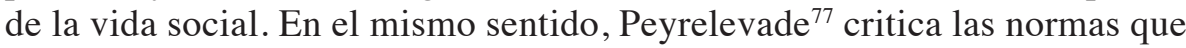
imponen a las empresas la obtención de rentabilidades excesivas e irracionales, pues a largo plazo ello compromete la realización del proyecto social que toda empresa se plantea. Frente a las tentaciones totalitarias del mercado, Farjat $^{78}$ propone la noción de economía de derecho, referida al ejercicio de un control jurídico del impacto del poder económico sobre la democracia. Así, se concibe para el sistema jurídico un rol prescriptivo de valores que deben ser atendidos en el funcionamiento ordinario del sistema económico.

La conveniencia de matizar las presiones hacia la generación de rentabilidades económicas es aceptada aun dentro del marco teórico propio de la administración de las empresas privadas, en el que se ha impuesto desde hace algún tiempo la noción de responsabilidad social de la empresa ${ }^{79}$. Un análisis, incluso somero, de esa institución desborda ampliamente el objeto de la presente reflexión. La pertinencia de invocarla deriva del hecho que ella plantea claramente la importancia de que los accionistas conciban, también en el ámbito de las empresas privadas, la existencia de responsabilidades empresariales diferentes a la mera generación de rentabilidad. Como es

73 Corte Constitucional. Sentencia C-074 de 1993.

74 LOMBARD. Les conséquences juridiques du passage de l'État propriétaire à l'État actionnaire: les contraintes du droit de la concurrence, cit.

75 MALECKI, C. L'État actionnaire, l'exemple atypique d'un grand actionnaire. En Cahiers de Droit de l'Entreprise. N. ${ }^{\circ}$ 5, septembre-octobre, 2005, 61-64.

76 Supiot,A.L'esprit de Philadelphie. La justice sociale face au marché total. Paris: Seuil, 2010.

77 Peyrelevade, J. Le capitalisme total. Paris: Seuil, 2005.

78 FarJat, G. Pour un droit économique. Paris: PUf, 2004, 188.

79 Navarro García, F. Responsabilidad social corporativa: teoría y práctica. Madrid: ESIC, 2012. 
natural, ese tipo de planteamiento resulta todavía más pertinente cuando el accionista es el Estado. Se llega de ese modo a un punto en el que resulta necesario fijar límites tanto a la racionalidad económica como a la jurídica.

\section{CONCLUSIONES}

Las políticas adoptadas en Francia y en Colombia con el fin de racionalizar la actividad del Estado como accionista presentan semejanzas y divergencias. En cuanto a las principales similitudes, encontramos que: a) se trata de políticas que han sido influenciadas de manera determinante por actores internacionales; b) son medidas que representan una toma de conciencia de los desafíos que implica para el Estado desarrollar eficazmente su rol como accionista; c) plantean la adopción de una nueva institucionalidad especializada en el ejercicio de las actividades como propietario; d) se proponen esencialmente objetivos de orden económico, consistentes en obtener un rendimiento adecuado del capital que el Estado tiene invertido en la empresas; e) se dirigen a separar la función de accionista que tiene el Estado, de otras actividades estatales, en especial, la regulación económica; f) tratan de aislar a las empresas de la influencia política de corto plazo, por lo que el centro de decisión empresarial tiende a trasladarse de las instancias de la Administración Pública a las esferas de dirección de las sociedades, como la junta directiva, y para lograr ese objetivo intentan dotar a las empresas de capital humano altamente calificado.

En cuanto a las diferencias, se destacan dos aspectos. De una parte, en Francia la institucionalidad encargada de realizar la función del Estado accionista es mucho más robusta que en Colombia. Es una nueva entidad pública que centraliza de manera efectiva todas esas funciones, desplazando de esa forma a otras autoridades, como los ministerios. En Colombia, por el contrario, se ha creado solamente una nueva dirección dentro del Ministerio de Hacienda, pero subsiste el poder de tutela que otros ministerios tienen sobre las empresas de su sector. Esto puede explicarse por el hecho de que en Colombia la política aún se encuentra en etapa de implementación, estando ya previsto crear en el futuro una entidad que centralice la función a nivel nacional. De otra parte, el dispositivo legal francés permite que la composición de la junta directiva de las empresas sea heterogénea, con presencia de actores provenientes de diferentes sectores. Por el contrario, en el caso colombiano, el Presidente de la República monopoliza la facultad de nominación de los miembros de los órganos de dirección a través de la designación de funcionarios de libre nombramiento y remoción. La composición independiente y plural de las juntas tiende a ser identificada como una característica de las empresas más eficientes. 


\section{REFERENCIAS}

Acemoglu, D. y Robinson, J. Por qué fracasan los países. Bogotá: Planeta, 2012.

Aftalion, F. La faillite de l'économie administrée. Paris: Puf, 1990.

Alviar, H. y Lamprea, E. (coords.). El Estado regulador en Colombia. Bogotá: Uniandes, 2015.

Autin, J. L. Réflexion sur l'usage de la régulation en droit public. En Maille, M. (ed.), La régulation entre droit et politique. Paris: L'Harmattan, 1995, 43-55.

Azema, D. L'impossible État actionnaire? Paris: L'Institut Montaigne, 2017.

BARBIER de La SERRE, R. Rapport "L'État actionnaire et le gouvernement des entreprises publiques”. Disponible en: http://www.ladocumentationfrancaise.fr/rapportspublics/034000095/index.shtml

BARrera, S. y López, E. L'entreprise d'État à Cuba: tensions et changement. En Cahiers des Amériques latines. N. . 84, 2017, 89-106.

Bernal, A. et al. Gobierno corporativo en América Latina. Importancia para las empresas de propiedad estatal. Caracas: CAF, 2012.

Bézard, B. y Preiss, É. L'agence des participations de l'État. En Revue française d'administration publique. N. . 4, 2007, 601-613.

Buchanan, J. y Tollison, R. The Theory of Public Choice. University of Michigan Press, 1984.

CArtier-Bresson, A. L'État actionnaire. Paris: LgdJ, 2010.

Cour des Comptes, L'État actionnaire. Paris: La Documentation Française, 2017.

Chevallier, J. L'État post-moderne. Paris: LGDJ, 2004.

Chevallier, J. L'État régulateur. En Revue française d'administration. ‥ 111, 2004/3.

Chevallier, J. De quelques usages du concept de régulation. En Miaille, M. (ed.), La régulation entre droit et politique. Paris: L'Harmattan, 1995, 71-93.

Delion, A. De l'État tuteur à l'État actionnaire. En Revue française d'administration publique. N. . 4, 2007, 537-572.

Deschamps, M. L'expert ou le peuple? Deux attitudes polaires face à la politique de concurrence. En RIDE. N. ${ }^{\circ} 1,2012,57-94$.

De Smet, F-J. Déclin du politique et gouvernance publique. En Thirion, N., Crise et droit économique. Bruxelles: Larcier, 2014, 27-50.

Duran, P. Piloter l'action publique, avec ou sans le droit. En Revue Politiques et management public. Vol. 11, n. ${ }^{\circ}$ 4, 1993, 1-45.

FarJat, G. Droit économique. Paris: puf, 1971.

FarJat, G. Pour un droit économique. Paris: PUf, 2004. 
Frison-Roche, M-A. Le modèle du marché. En Archives de philosophie du droit. Vol. 40, 1995, 286-313.

Frison-Roche, M-A. Qu'est-ce que le service public? Point de vue juridique. En Revue de l'énergie. $\mathrm{N}$. $486,1997$.

Ganga, F. y Vera, J. El gobierno corporativo: consideraciones y cimientos teóricos. En Cuadernos de Administración. Vol. 21, n. ${ }^{\circ}$ 35, 2008, 93-126.

García-Pelayo, M. Burocracia y tecnocracia. Madrid: Alianza, 1987.

Gargarella, R. Crisis de la representación política. México: Fontamara, 1997.

Jeammaud, A. Introduction à la sémantique de la régulation juridique. En Clam, J. y Gilles, M. (eds.), Les transformations de la régulation juridique. Paris: LGDJ, 1998, 47-72.

Jensen, M. y Meckling, W. Theory of the Firm: Managerial Behavior, Agency Costs and Ownership Structure. En Journal of Financial Economics. Vol. 3, n. ${ }^{\circ}$ 4, 1976, 305-360.

LATORRe, I. La política de mejora regulatoria: oportunidades y desafíos para Colombia. En Revista de Derecho Público, Universidad de los Andes. N. ${ }^{\circ} 33,2014,2-35$.

Levi-Faur, D. y Jordana, J. The Rise of Regulatory Capitalism: The Global Diffusion of a New Order. En The Annals of the American Academy of Political and Social Science. Vol. 598, n. ${ }^{\circ} 1,200-217$.

Lyotard, J-F. La condition postmoderne, Paris: Minuit, 1979.

Lombard, M. Les conséquences juridiques du passage de l'État propriétaire à l'État actionnaire: les contraintes du droit de la concurrente. En Revue française d'administration publique. N. ${ }^{\text {4 }}$, 2007, 573-584.

López Medina, D. El sueño weberiano: claves para una comprensión constitucional de la estructura administrativa del Estado colombiano. En Revista de Derecho Público, Universidad de los Andes. Vol. 19, 2006.

LOUVARIs, A. Lois techniciennes et droit à un procès équitable: le cas des lois de régulation économique. En Les Petites affiches. N. ${ }^{\circ}$ 134, 60-63.

Majone, G. La Communauté européenne, un État régulateur. Paris: Montchrestien, 1996.

Majone, G. From the Positive to the Regulatory State: Causes and Consequences of Chanmges in the Mode of Governance. En Journal of Public Policy. Vol. 17, n. ${ }^{\circ} 2$, 1997, 139-167.

MALECKI, C. L'État actionnaire, l'exemple atypique d'un grand actionnaire. En Cahiers de Droit de l'Entreprise. ‥ ${ }^{\circ}$, 2005, 61-64.

Murillo de La Cueva, F. Ideología, tecnocracia y liberalismo. En Revista Barataria Castellano-Manchega de Ciencias Sociales. N. . 6, 2003-2004, 47-72.

NAVARRo, F. Responsabilidad social corporativa: teoría y práctica. Madrid: esIC, 2012. 
OCDE, Directrices sobre el gobierno corporativo de las empresas públicas, Paris: OCDE Publising 2011.

Peyrelevade, J. Le capitalisme total, Paris: Seuil, 2005.

Prétot, X. L'administration des entreprises publiques: A propos de la loi no 83-675 du 26 juillet 1983 rélative a la démocratisation du secteur public. En Revue Administrative. Vol. 37, n. ${ }^{\circ} 217,1984,29-38$.

Ramos Jiménez, A. Las formas modernas de la política. Estudio sobre la democratización de América Latina. Mérida: cIPC, 2016.

ReCODER De CASSo, J. El papel de los independientes en los consejos. Una prioridad mundial. En Boletín Económico del ICE. 2006, 15-30.

RestREPO-MEDina, M. Redefinición normativa de la regulación y el control de la actividad económica en el caso colombiano. En Universitas. Vol. 59, n. . 121, 2010, 263-304.

Rosanvallon, P. Le capitalisme utopique, histoire de l'idée de marché. Paris: Seuil, 1999.

Rosanvallon, P. La légitimité démocratique. Impartialité, réflexivité, proximité. Paris: Le Seuil, 2008.

Rosanvallon, P. La contre-démocratie. La politique à l'âge de la défiance. Paris: Seuil, 2006.

Rosenstein, S. y Wyat, J. Outside Directors, Board Independence, and Shareholder Wealth. En Journal of Financial Economics. Vol 26, n. ${ }^{\circ} 2,1990,175-191$.

Rouban, L. Le pouvoir anonyme: les mutations de l'État à la française. Paris: Presses de Sciences Politiques, 1994.

Sanclemente-Arciniegas, J. L'indépendance du régulateur en France et en Colombie. Tesis de doctorado en Derecho, Universidad Paris-Dauphine, PSL, 2016.

SASSEN, S. Desnacionalización de las políticas estatales y privatización de la producción de normas. En Teubner, G., SAssen, S. y Krasner, S., Estado, soberano y globalización. Bogotá: Siglo del Hombre Editores, 2010, 103-138.

SÈve, R. Presentation. En Le privé et le public, Archives de philosophie du droit. N. ${ }^{\circ} 41$, 1997, 9-12.

Stigler, G. The Theory of Economic Regulation. En The Bell Journal of Economics and Management Science. 1971, 3-21.

Supiot, A. L'esprit de Philadelphie. La justice sociale face au marché total. Paris: Seuil, 2010.

The World Bank. Corporate Governance of State-Owned Enterprises. Washington D.C., 2014.

The World Bank. China's Management of Enterprise Assets: The State as Shareholder. Washington D.C., 1997.

The World Bank. Bureaucrats in Business. The Economics and Politics of Government Ownership, Washington D.C., 1995. 
Teubner, G. Elementos materiales y reflexivos en el derecho moderno. En Bourdieu, P. y Teubner, G., La fuerza del derecho. Bogotá: Uniandes, Universidad Javeriana y Siglo del Hombre Editores, 2000, 81-152.

Von Tunzelmann, N. Historical Coevolution of Governance and Technology in the Industrial Revolutions. En Structural Change and Economic Dynamics. Vol. 14, n. ${ }^{\circ} 4$, 2003, 365-384.

Würtenberger, T. y Neidhardt, S. L'État actionnaire en Allemagne. En Revue française d'administration publique. N. . 4, 2007, 585-599. 